\title{
Genetic induction of structural changes in barley chromo- somes added to common wheat by a gametocidal chromosome derived from Aegilops cylindrica
}

\author{
Fang Shi and Takashi R. Endo* \\ Laboratory of Plant Genetics, Graduate School of Agriculture, \\ Kyoto University, Kyoto 606-8502, Japan
}

(Received 19 May 1999, accepted 21 June 1999)

\begin{abstract}
A gametocidal chromosome, chromosome 2C derived from Aegilops cylindrica, was introduced into six wheat-barley addition lines to establish chromosome-mutationinducing lines. These lines, except the one for chromosome $4 \mathrm{H}$, had a pair of respective barley chromosomes and one $2 \mathrm{C}$ chromosome $\left(22^{\prime \prime}+1^{\prime}\right)$; the line for $4 \mathrm{H}$ was doubly monosomic for chromosome $4 \mathrm{H}$ and chromosome $2 \mathrm{C}(21 "+2$ '). In these lines, chromosome breaks were expected to occur in the gametes lacking chromosome 2C. The selfed and backcrossed progeny of these lines were cytologically investigated by in situ hybridization and N-banding. Various types of structural aberration like deletion and translocation were detected for all barley chromosomes with frequencies ranging from $10.8 \%$ to $27.9 \%$. The highest frequency of aberrations occurred in chromosome $4 \mathrm{H}$ with most of the breakpoints localized in or near the centromeric region. A simplified procedure of in situ hybridization used in this study was suitable for the large-scale screening for barley chromosome aberrations in the background of wheat.
\end{abstract}

\section{INTRODUCTION}

To know the precise location of genes controlling agronomically important traits is a prerequisite for successful breeding programs. A series of aneuploid stocks developed in a common wheat cultivar Chinese Spring have greatly contributed to localize genes on chromosomes and chromosome arms in the wheat genome (Sears, 1954, 1966; Sears and Sears, 1978; McIntosh, 1988). A series of deletion stocks of common wheat were isolated from chromosomal structural changes induced in the progeny of Chinese Spring bearing a gametocidal chromosome 2C which is derived from Aegilops cylindrica (Endo, 1988; Endo and Gill, 1996). The deletion stocks have been proved to be useful in localizing genes and DNA markers to interval regions or chromosome sub-arms between the breakpoints of two deletions (Delaney et al., 1995; Gill et al., 1993, 1996; Hohmann et al., 1995; Kota et al., 1993).

It is also desirable to develop aneuploid stocks in barley which would allow the physical localization of genes on chromosomes. However, cytogenetic stocks such as aneuploids and deletion lines are either very difficult or impossible to maintain in barley as it is a diploid. To date, various techniques have been used to conduct physical

\footnotetext{
* Corresponding author.
}

mapping in barley, such as PCR mediated localization of DNA sequences on microisolated translocation chromosomes (Sorokin et al. 1994), pulsed field gel electrophoresis (Siedler and Graner, 1991), and in situ hybridization (Butnaru et al, 1998). However, these methods are technically cumbersome and have their limitations.

Islam et al. (1978) produced six wheat-barley disomic addition lines in which a pair of six barley chromosomes, except $1 \mathrm{H}$, were introduced respectively into a hexaploid wheat cultivar Chinese Spring. It was expected that chromosome $2 \mathrm{C}$, which induces chromosome mutations in Chinese Spring, would also induce chromosomal aberrations in the wheat-barley addition lines and that structural changes induced in wheat and barley chromosomes would be tolerated thanks to the hexaploid nature of the alien addition lines. In addition, another gametocidal chromosome 3C, derived from Ae. triuncialis, has also been shown to induce structural changes in rye chromosome $1 \mathrm{R}$ substituting for wheat chromosome 1B (Endo et al. 1994, 1998). With the view of inducing structural changes in barley chromosomes, Shi et al. (1997) introduced chromosome $2 \mathrm{C}$ into the six wheat-barley addition lines. Schubert et al. (1998) preliminarily proved the practicability of generating wheat lines carrying barley chromosome deletions and translocations. In this study the induction of chromosomal structural changes by chromo- 
some 2C were investigated in all six wheat-barley addition lines, using a simplified in situ hybridization procedure to facilitate the large-scale screening of aberrant barley chromosomes.

\section{MATERIALS AND METHODS}

Plant materials. Materials used in the present study were produced by Shi et al. (1997). They were six barley/ $2 \mathrm{C}$ addition lines of the common wheat cultivar Chinese Spring. All the lines except the one for barley chromosome $4 \mathrm{H}$ were disomic for the respective barley chromosomes and monosomic for chromosome $2 \mathrm{C}(22$ " +1 '). The line for $4 \mathrm{H}$ was doubly monosomic for chromosome $4 \mathrm{H}$ and chromosome 2C (21" +2 '). These lines were either backcrossed as female with the respective wheat-barley addition lines or self-pollinated. Chromosome mutations were expected to occur in the gametes of these lines in which chromosome $2 \mathrm{C}$ was not present (Fig. 1).

Cytology. Structural changes in barley chromosomes were identified by N-banding, fluorescence in situ hybridization (FISH), genomic in situ hybridization (GISH). The FISH probe was one of the barley subtelomeric sequences (HvT01) which is repeated in tandem arrays and is closely associated with the telomeric repeats
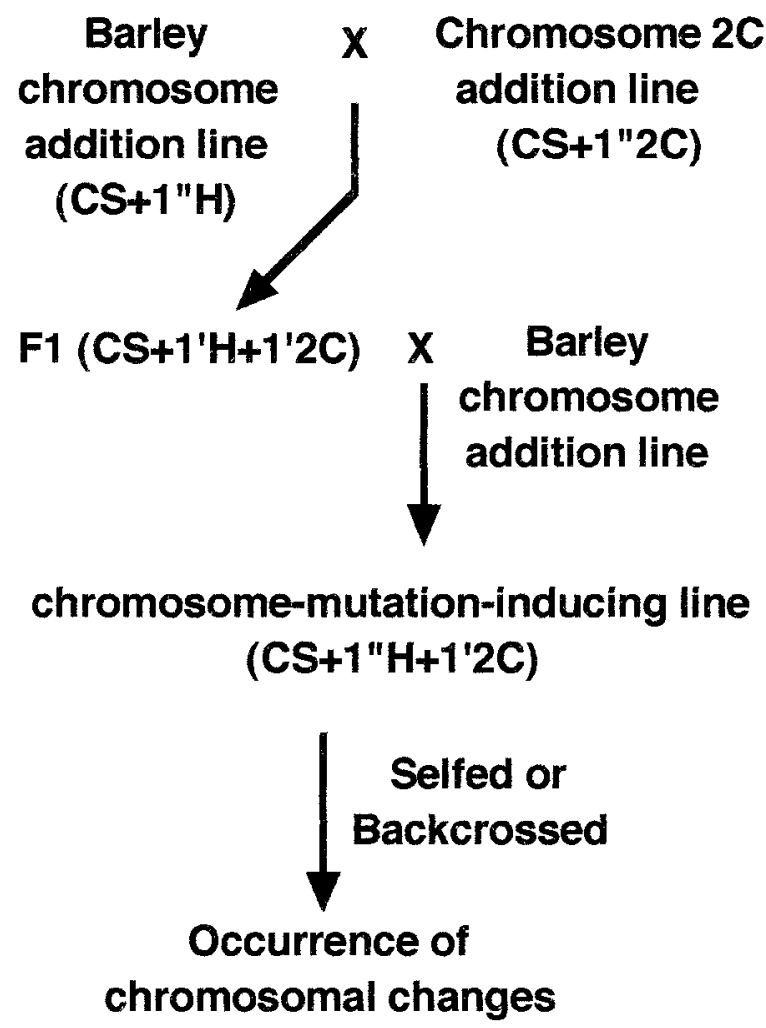

Fig. 1. Procedure for the genetic induction of structural changes in barley chromosomes added to common wheat. $\mathrm{CS}, \mathrm{H}$, and $2 \mathrm{C}$ stand for Chinese Spring wheat, barley chromosome, and chromosome $2 \mathrm{C}$, respectively.
(Belostotsky and Ananiev, 1990; Roder et al., 1993). This probe was labeled with Dig-dUTP (Boehringer) via PCR amplification as described by Schubert et al. (1998), using the total barley genomic DNA or HvT01 clone as template and a primer set designed by Yoshino et al. (1998). The total barley genomic DNA was used for the GISH probe. The detailed procedures of FISH and GISH used in this study were mostly as described by Schubert et al. (1998), except that the denaturation of chromosomal DNAs on slides was always conducted with $1 \mathrm{M} \mathrm{NaH}_{2} \mathrm{PO}_{4}$ solution at $88-92^{\circ} \mathrm{C}$ and that the washing steps after hybridization and detection processes were minimized as follows. After hybridization, cover slips were allowed to slip off naturally in $2 \times \mathrm{SSC}$, slides were briefly rinsed with distilled water, quickly dried with a puffer, and antidigoxigenin- fluorescein Fab fragments (Boehringer) in 4 $\times \mathrm{SSC}$ and $1 \%$ bovine serum albumin $(4 \mu \mathrm{g} / \mathrm{ml})$ were applied to slides (10 $\mu \mathrm{l}$ per slide). Slides were covered with cover slips and kept in a dark, humid chamber for 0.5 to $1 \mathrm{~h}$ at $37^{\circ} \mathrm{C}$. Cover slips were allowed to fall off naturally in $2 \times \mathrm{SSC}$, slides were rinsed with distilled water, and quickly dried with a puffer, and mounted with an antifade solution of diazobicyclo-octane (2.33\% DABCO, polysciences Inc.) containing $1 \mu \mathrm{g} / \mathrm{ml}$ propidium iodide (PI) for observation. N-banding was conducted as described by Endo and Gill (1984) using the same $1 \mathrm{M} \mathrm{NaH} \mathrm{PO}_{4}$ solution as the one used for the denaturation in FISH and GISH. Sequential N-banding and in situ hybridization on the same mitotic metaphase cells was conducted using the N-banded slides which was destained in $70 \%$ and $99 \%$ ethanol, until no stain was visible, and air dried. The slides were used for in situ hybridization either directly or after being treated again with a hot $1 \mathrm{M} \mathrm{NaH} \mathrm{NO}_{4}$ solution. The subsequent in situ hybridization procedure was the same as describe above.

Microphotographing. Fuji Minicopy HRII films were used for microphotography of N-banded chromosomes and Fuji negative color films (ISO 400) were used for recording FISH and GISH signals. The chromosome images on the negatives were digitised with a film scanner, processed, and printed with a digital printer.

\section{RESULTS AND DISCUSSION}

The FISH signals were generated on both terminal regions of all six barley chromosomes added to Chinese Spring (Fig. 2A). Therefore, the absence of the HvT01 signal was regarded as a criterion for structural aberrations having occurred in the barley chromosomes. The FISH analysis detected a total of 85 plants carrying aberrant barley chromosomes in the progeny of the six barley/ 2C lines (Table 1). Eight of them had two aberrant barley chromosomes, one with the barley centromere and one with the wheat centromere. This was probably caused by 

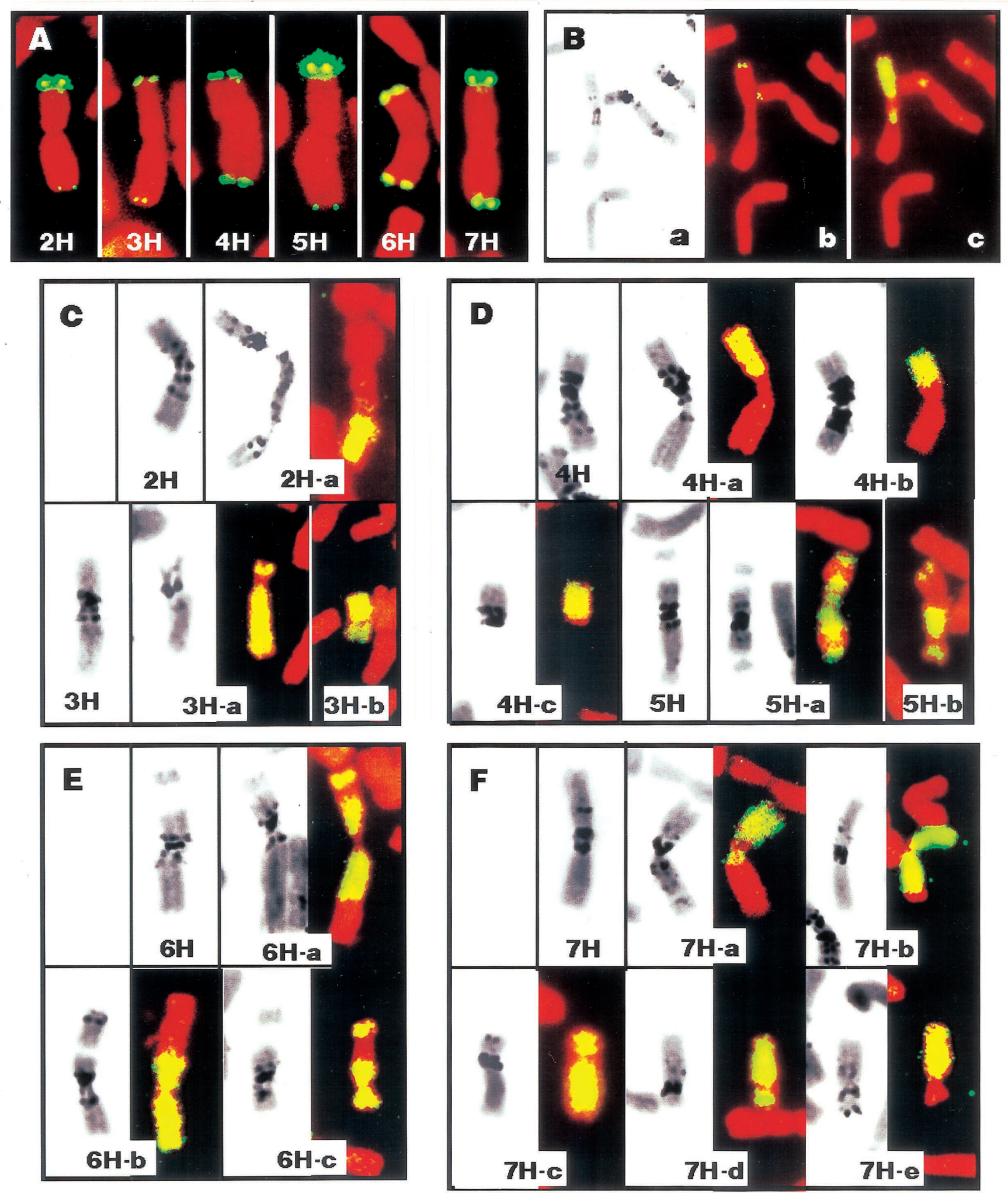

Fig. 2. (A) FISH signals of six barley chromosomes. (B) Sequential N-banding, FISH, and GISH of a 7H/wheat chromosome translocation. (C) N-banding of normal $2 \mathrm{H}$ and $3 \mathrm{H}$ chromosomes, and $\mathrm{N}$-banding and GISH of aberrant $2 \mathrm{H}$ and $3 \mathrm{H}$ chromosomes. See the text for details. (D) N-banding of normal $4 \mathrm{H}$ and $5 \mathrm{H}$ chromosomes, and $\mathrm{N}$-banding and GISH of aberrant $4 \mathrm{H}$ and $5 \mathrm{H}$ chromosomes. See the text for details. (E) N-banding of normal $6 \mathrm{H}$ chromosome and N-banding and GISH of aberrant $6 \mathrm{H}$ chromosomes. See the text for details. (F) N-banding of normal 7H chromosome, and N-banding and GISH of aberrant $7 \mathrm{H}$ chromosomes. See the text for details. 
Table 1. Frequency of plants with aberrant barley chromosomes

\begin{tabular}{cccccc}
\hline \hline \multirow{2}{*}{$\begin{array}{c}\text { Barley } \\
\text { chromosome }\end{array}$} & \multicolumn{2}{c}{ Selfed progeny } & & \multicolumn{2}{c}{ Backcrossed progeny } \\
\cline { 2 - 3 } \cline { 5 - 6 } & $\begin{array}{c}\text { No. plants } \\
\text { examied }\end{array}$ & $\begin{array}{c}\text { No. plants with } \\
\text { aberration }(\%)\end{array}$ & & $\begin{array}{c}\text { No. plants } \\
\text { examined }\end{array}$ & $\begin{array}{c}\text { No. plants with } \\
\text { aberration }(\%)\end{array}$ \\
\hline $2 \mathrm{H}$ & 15 & $1(6.7)$ & & 22 & $3(13.6)$ \\
$3 \mathrm{H}$ & 35 & $2(5.7)$ & & 60 & $9(15.0)$ \\
$4 \mathrm{H}$ & 48 & $16(33.3)$ & & 20 & $3(15.0)$ \\
$5 \mathrm{H}$ & 7 & $1(14.3)$ & & 18 & $3(16.7)$ \\
$6 \mathrm{H}$ & 43 & $8(18.6)$ & & 51 & $7(13.7)$ \\
$7 \mathrm{H}$ & 28 & $6(21.4)$ & & 156 & $26(16.7)$ \\
Total & 176 & $34(19.3)$ & & 327 & $51(15.6)$ \\
\hline
\end{tabular}

the transposition of a broken segment of a barley chromosome onto a wheat chromosome. For barley chromosomes $2 \mathrm{H}, 3 \mathrm{H}, 5 \mathrm{H}, 6 \mathrm{H}$, and $7 \mathrm{H}$, structural changes were detected in $5.7-21.4 \%$ of the selfed progeny and in $13.6-16.7 \%$ of the backcrossed progeny (Table 1). These frequencies are comparable to those reported by Schubert et al. (1998) for chromosome $7 \mathrm{H}$ in an independently conducted study (9.7\% in the backcrossed progeny, $20.4 \%$ in the selfed progeny). Aberrant $4 \mathrm{H}$ chromosomes were found in $33.3 \%$ of the selfed progeny and $15.0 \%$ of the backcrossed progeny of the $4 \mathrm{H} / 2 \mathrm{C}$ line (Table 1 ). Considering that this line was monosomic for $4 \mathrm{H}$, this frequency is much higher than those for the other barley chromosomes. Aberrant $3 \mathrm{H}$ chromosomes were detected more often in the backcrossed progeny than in the selfed one, and aberrant $4 \mathrm{H}$ and $7 \mathrm{H}$ chromosomes were found significantly more often in the selfed progeny than in the backcrossed one. These higher frequencies of aberrations in the selfed progeny might be explained in part by the preferential transmission of aberrant barley chromosomes through pollen.

After FISH analysis, aberrant barley chromosomes were further analysed by N-banding and GISH when extra roottips of the critical plants were available. Fifty-nine aberrant barley chromosomes were successfully analysed by separate N-banding and GISH using different root-tips of the same plants or sequential N-banding and GISH on the same metaphase cell. The type of aberration, deletion or translocation, was determined by GISH, and the barley chromosome arms involved in the aberrations were revealed by a combination of N-banding and GISH. In most cases separate N-banding and GISH analyses were sufficient to determine the barley chromosome arms involved because the aberrant barely chromosomes usually had either changed morphology (e.g. skewed arm ratios) or N-banding patterns, or both. The sequential $\mathrm{N}$ banding and GISH analysis allowed the unambiguous identification of the type of aberration and barley chromosome arms involved. Fig. $2 \mathrm{~B}$ shows an example of sequential $\mathrm{N}$ - banding-FISH-GISH of a $7 \mathrm{H}$ aberration on the same cell. (The destained N-banded slide was used without denaturing for FISH, and the FISH slide was rinsed with distilled water to remove the antifade solution, dehydrated in 99\% ethanol, air-dried, and denatured with a $1 \mathrm{M} \mathrm{NaH} \mathrm{PO}_{4}$ solution for GISH.) Without conducting sequential N-banding and GISH it would have been difficult to determine which $7 \mathrm{H}$ arm had the translocation point. Some other representative aberrations are shown in Fig. 2C-F. Sequential N-banding and GISH were conducted in $4 \mathrm{H}-\mathrm{a}, 4 \mathrm{H}-\mathrm{b}$, and $4 \mathrm{H}-\mathrm{c}$ (Fig. 2D) and 7Ha (Fig. 2F). The other aberrant barley chromosomes were analysed by separate N-banding and GISH. Hybridization signals of GISH were not shown in the nucleolar organizing regions (NORs) of $5 \mathrm{H}$ and $6 \mathrm{H}$ : red regions flanked by greenish yellow hybridization signals (see 5H-a and -b in Fig. 2D, 6H-a and -c in Fig. 2E) and centromeric regions. This is probably due to the sequence similarity of the NORs and centromeric regions (AragonAlcaide, 1996; Jiang et al., 1996; Presting et al., 1998) between wheat and barley.

Thus, 31 deletions, 26 translocations and 2 isochromosomes were identified. Of the 31 deletions 15 were telosomes ( 4 of $3 \mathrm{HS}, 5$ of $4 \mathrm{HS}, 1$ of $6 \mathrm{HS}, 1$ of $7 \mathrm{HS}, 1$ of $4 \mathrm{HL}, 1$ of $6 \mathrm{HL}$, and 2 of unknown chromosome arms; see $4 \mathrm{H}$-c in Fig. 2D). The other 16 had breakpoints in the barley chromosome arms: six in the short arms (1 in $3 \mathrm{HS}$, 3 in $6 \mathrm{HS}, 2$ in $7 \mathrm{HS}$; i.e. $3 \mathrm{H}$-a in Fig. $2 \mathrm{C}$ and $7 \mathrm{H}-\mathrm{c}$ in Fig. $2 \mathrm{~F}$ ), six in the long arms ( 1 in $5 \mathrm{HL}, 2$ in $6 \mathrm{HL}, 3$ in $7 \mathrm{HL}$; i.e. 5H-b in Fig.2D, 6H-c in Fig. 2E, and 7H-d in Fig. 2F), one in both arms ( 1 in $3 \mathrm{H}$; $3 \mathrm{H}-\mathrm{b}$ in Fig. $2 \mathrm{C}$ ), and three in unknown chromosome arms. Three types of translocation were found among the 26 translocations: 12 were Robertsonian, 12 were classified as wheat-to-barley translocations (barley chromosomes with wheat chromosomal segments), and two were classifed as barley-to-wheat translocations (wheat chromosomes with barley chromosomal segments). Of the 12 Robertsonian translocations eight involved 4HS (i.e. 4H-a in Fig. 2D), one involved 5HS, one involved 7HS (7H-e in Fig. F), and two involved 4HL. Two of the 12 wheat-to-barley translocations had translocation points in $2 \mathrm{HS}$ (i.e. $2 \mathrm{H}$-a in Fig. $2 \mathrm{C}$, dicentric), three in $6 \mathrm{HS}$ (i.e. $6 \mathrm{H}$-b in Fig. $2 \mathrm{E}$ ), one in $7 \mathrm{HS}$, one in $4 \mathrm{HL}$, two in $6 \mathrm{HL}$ (i.e. $6 \mathrm{H}$-a in Fig. $2 \mathrm{E}$ ), two in $7 \mathrm{HL}(7 \mathrm{H}-\mathrm{a}$ and $-\mathrm{b}$ in Fig. 2F), and one in an unknown chromosome 
arm. One of the two barley-to-wheat translocations had a major part of $4 \mathrm{HS}$ translocated to the long arm of wheat chromosome 4B (4H-b in Fig. 2D). The other one contained a $7 \mathrm{H}$ interstitial chromosomal segment within a wheat chromosome. The two isochromosomes were from the short arms of chromosome $5 \mathrm{H}$ (5H-a in Fig. 2D) and chromosome $6 \mathrm{H}$, respectively

The breakpoints of the deletions and translocation seem to be localized in general to the distal and proximal regions. Especially for $4 \mathrm{H}$, most of the chromosome breaks occurred at or near the centromere (6 telosomes and 10 Robertsonian translocations out of the 19 identified aberrant $4 \mathrm{H}$ chromosomes). The predominance of 4HS over 4HL in the telosomes and Robertsonian translocations (13 to 3 ) may result from pollen carrying $4 \mathrm{HL}$ being at a disadvantage during fertilization.

The chromosome constitutions of 12 arbitrarily chosen plants carrying chromosomal aberrations were studied in the next generation. The critical aberrant barley chromosomes were found again in all the progenies but one. The aberrant barley chromosome which was not recovered in the progeny might have been lost in the germ cells of the parental plant because 12 progeny plants were examined. Thus, it was demonstrated that the gametocidal chromosome $2 \mathrm{C}$ could induce various types of structural change in every barley chromosome added to common wheat and that such structural changes could be transmitted to the progeny. The high induction rate of the barley chromosome aberrations, together with their high transmission rate, will facilitate the generation of aberrant barley chromosome lines of common wheat. These lines will be useful in mapping genes and DNA sequences on barley chromosomes and also in studying how barley genes function in wheat genomic environments.

We are grateful to I. P. King for his critical reading of the manuscript. This study was supported in part by a Grant-inAid for Scientific Research (A) (No. 08406001) from the Ministry of Education, Science, Sports, and Culture of Japan. Contribution No. 558 from the Laboratory of Plant Genetics, Graduate School of Agriculture, Kyoto University, Japan.

\section{REFERENCES}

Aragon-Alcaide, L., Miller, T., Schwarzacher, T., Reader, S., and Moore, G. (1996) A cereal centromeric sequence. Chromosoma 105, 261-268.

Belostotsky, D. A., and Ananiev, E. V. (1990) Characterization of relic DNA from barley genome. Theor. Appl. Genet. 80, $374-380$.

Butnaru, G., Chen, J., Goicoechea, P., and Gustafson, J. P. (1998) In situ hybridization mapping of genes in Hordeum vulgare L. J. Hered. 89, 366-370.

Delaney, D. E., Nasuda, S., Endo, T. R., Gill, B. S., and Hulbert, S. H. (1995) Cytologically based physical maps of the group2 chromosomes of wheat. Theor. Appl. Genet. 91, 568-573.
Endo, T. R. (1988) Induction of chromosomal structural changes by a chromosome of Aegilops cylindrica L. in common wheat. J. Hered. 79, 366-370.

Endo, T. R., and Gill, B. S. (1996) The deletion stocks of common wheat. J. Hered. 87, 295-307.

Endo, T. R., and Gill, B. S. (1984) Somatic karyotype, heterochromatin distribution, and nature of chromosome differentiation in common wheat, Triticum aestivum L. em Thell. Chromosoma 89, 361-369.

Endo, T. R., Yamamoto, M., and Mukai, Y. (1994) Structural changes of rye Chromosome $1 \mathrm{R}$ induced by a gametocidal chromosome. Jpn. J. Genet. 69, 13-19.

Endo, T. R., Shi, F., and Tsvetkov, K. S. (1998) Genetic induction of chromosomal structural changes of alien chromosomes in common wheat. Proc. 9th Int. Wheat Genet. Symp., Saskatoon, Canada 2, 40-43.

Gill, K. S., Gill, B. S., Endo, T. R., and Mukai, Y. (1993) Fine physical mapping of $\mathrm{Ph} 1$, a chromosome pairing regulator gene in polyploid wheat. Genetics 134, 1231-1236.

Gill, K. S., Gill, B. S., Endo, T. R., and Boyko, E. V. (1996) Identification and high-density mapping of gene-rich regions in chromosome group 5 of wheat. Genetics 143, 1001-1012.

Hohmann, U., Graner, A., Endo, T. R., and Gill, B. S., Herrmann, R. G., (1995) Comparison of wheat physical maps with barley linkage maps for group 7 chromosomes. Theor. Appl. Genet. 91, 618-626.

Islam, A. K. M. R., Shepherd, K. W. and Sparrow, D. H. B. (1978) Production and Characterization of wheat-barley addition lines. Proc. 5th Int. Wheat Genet. Symp., New Delhi, India, 365-371.

Jiang, J., Nasuda, S., Dong, F., Scherrer, C. W., Woo, S.-S., Wing, R. A., Gill, B. S., and Ward, D. C. (1996) A conserved repetitive DNA element located in the centromeres of cereal chromosomes. Proc. Natl. Acad. Sci. USA 93, 1421014213.

Kota, R. S., Gill, K. S., and Gill, B. S., and Endo, T. R. (1993) A cytogenetically based physical map of chromosome 1B in common wheat. Genome 36, 548-554.

Mclntosh R. A. (1988) Catalogue of gene symbols for wheat. Proc. 7th Int. Wheat Genet. Symp., Cambridge, UK, 1225-1323.

Presting, G. G., Malysheva, L, Fuchs, J., and Schubert, I. (1998) A TY3/GYPSY retrotransposon-like sequence localizes to the centromeric regions of cereal chromosomes. Plant J. 16, 721728.

Roder, M. S., Lapitan, N. L. V., Sorrells, M. E., and Tanksley, S. D. (1993) Genetic and physical mapping of barley telomeres. Mol. Gen. Genet. 238, 294-303.

Schubert, I., Shi, F., Fuchs, J., and Endo, T. R. (1998) An efficient screening for terminal deletions and translocations of barley chromosomes added to common wheat. Plant J. 14, 489-495.

Sears, E. R. (1954) The aneuploids of common wheat. Mo. Agr. Exp. Sta. Res. Bull 572, 1-58.

Sears, E. R. (1966) Nullisomic-tetrasomic combinations in Hexaploid wheat. In: chromosome manipulation and plant genetics (Lewis DR, ed). London: Oliver and Boyd, 29-47

Sears, E. R., and Sears, L. M. S. (1978) The telocentric chromosomes of common wheat. Proc. 5th Int. Wheat Genet. Symp., New Delhi, India, 389-407.

Shi, F., and Endo, T. R. (1997) Production of wheat-barley disomic addition lines possessing an Aegilops cylindrica gametocidal chromosome. Genes Genet. Syst. 72, 243-248.

Siedler, H., and Graner, A. (1991) Construction of physical maps of the Hor 1 locus of two barley cultivars by pulsed field gel electrophoresis. Mol. Gen. Genet. 226, 177-181.

Sorokin, A., Marthe, F., Houben, A., Pich, U., Graner, A., and Kunzel, G. (1994) Polymerase chain reaction mediated local- 
ization of RFLP clones to microisolated translocation chromosomes of barley. Genome 37, 550-555.

Yoshino, M., Nasuda, S., and Endo, T. R. (1998) Detection of ter- minal deletions in barley chromosomes by the PCR-based method. Genes Genet. Syst. 73, 163-166. 